\title{
A convergência tecnológica líquida no contexto da sala de aula: um recorte do ensino superior público baiano sob a ótica discente
}

\section{David Moises Barreto dos Santos ${ }^{1}$, Adolfo Almeida Duran² (Co-orientador), Teresinha Fróes Burnham ${ }^{3}$ (Orientadora)}

${ }^{1}$ Departamento de Ciências Exatas - Universidade Estadual de Feira de Santana (UEFS) Avenida Transnordestina, s/n - Novo Horizonte - 44.036-900 - Feira de Santana - BA

${ }^{2}$ Instituto de Matemática - Universidade Federal da Bahia Avenida Ademar de Barros s/n - Campus Ondina - Salvador - BA

${ }^{3}$ Departamento de Educação - Faculdade de Educação - Universidade Federal da Bahia Avenida Reitor Miguel Calmon s/n - Campus Canela - 40.110-100 - Salvador - BA

davidmbs@uefs.br, adolfo@ufba.br, tfroesb@ufba.br

Resumo. Temos presenciado na sociedade e, em especial, nas salas de aulas um fenômeno que chamamos convergência tecnológica líquida, caracterizado, dentre outras coisas, por uma proliferação de ciberinstrumentos móveis. $O$ seu uso não necessariamente tem tido uma orientação pedagógica, o que constitui um cenário desafiador. Neste sentido, o objetivo desta tese é investigar e discutir a relação da convergência tecnológica líquida no contexto da sala de aula a partir da percepção de estudantes da educação superior pública da Bahia. Com base na etnografia, desenvolvemos a pesquisa a partir de três turmas de três universidades diferentes, o que nos permitiu adentrar no cotidiano universitário, enriquecendo-a.

Abstract. We have seen in university classrooms a phenomenon which we call liquid technological convergence, characterized, in short, by a proliferation of mobile cyberinstruments. The use of such ciberinstrumentos not necessarily have had a pedagogical orientation, which turns out to be a challenging environment. In this sense, the objective of this thesis is to investigate and discuss the relationship of liquid technological convergence in the classroom from the student perspective within the context of Bahia public higher education. Based on ethnography, the research was conducted in three classes in three different universities. This allowed us to enter the routine university, enriching the research.

\section{Introdução}

Temos notado uma presença cada vez mais frequente e marcante dos mais diversos ciberinstrumentos móveis - netbooks, tablets, etc - em sala de aula, inclusive - e talvez principalmente - no ambiente universitário. Ciber por serem pontos de acesso ao ciberespaço e instrumentos por serem meios de mediação simbólica do sujeito com o mundo [Vigotski, 2007]. É uma convergência tecnológica líquida caracterizada pela 
proliferação e coexistência de diferentes ciberinstrumentos móveis que se intercomunicam, em escala mundial, permitindo que fluxos info-comunicacionais digitais, de qualquer natureza, passem por eles fluidamente.

No Brasil, a taxa de crescimento de vendas de ciberinstrumentos móveis já começa a ser maior do que a dos não móveis como computadores desktop [Barbosa, 2010; Barbosa, 2011; Smith, 2010]. Nos Estados Unidos, uma pesquisa entre graduandos indicou que 89\% possuem ou notebook ou netbook [Dahlstrom et al, 2011].

Entretanto, esse uso de ciberinstrumentos móveis não tem acontecido de forma orientada pedagogicamente, mas sim de maneira espontânea por parte dos próprios educandos. Após uma pesquisa sobre o estado da arte desta temática identificamos 6 lacunas de pesquisa [Santos, Duran \& Burnham, 2012]: (1) foco na coletividade, já que o interesses dos trabalhos publicados até então estão voltados para práticas individuais na sala de aula; (2) consideração de outros ciberinstrumentos que não apenas laptops, pois na maioria dos casos envolve apenas este tipo de ciberinstrumento; (3) ponderação de vantagens e desvantagens em vez de polarizar a discussão para apenas um dos lados; (4) uso de técnicas qualitativas, uma vez que metodologicamente a prioridade tem sido dada quase que exclusivamente a técnicas quantitativas; (5) realidades fora do eixo dos países desenvolvidos como o Brasil, pois grande parte das pesquisas tem se concentrado, sobretudo, em universidades americanas e canadenses; (6) necessidade de análises multidisciplinares, pois tem sido considerado apenas uma vertente disciplinar, geralmente ou da psicologia ou da educação.

Tentado suprir tal lacuna, o objetivo central dessa tese é caracterizar o fenômeno da convergência tecnológica líquida com o contexto da sala de aula a partir de um recorte da educação superior pública na Bahia sob a ótica discente. Para alcançar essa finalidade, traçamos três objetivos específicos: (1) aprofundar o entendimento do conceito de convergência tecnológica dada a sua marcante polissemia; (2) identificar e destacar as características, benefícios e desafios da convergência tecnológica líquida no contexto das salas de aulas da educação superior baiana selecionadas; (3) analisar a relação entre convergência tecnológica líquida e o foco atencional dos estudantes nos espaços investigados sob uma perspectiva multidisciplinar, envolvendo dispositivos teóricos da Psicologia Cognitiva, Educação e Sociologia.

\section{Metodologia}

Buscando cumprir o objetivo traçado, inicialmente, nos dedicamos a duas atividades em paralelo: (1) dada a polissemia do termo convergência tecnológica, fizemos uma investigação das diversas acepções atribuídas nas mais diversas áreas [Santos, Duran \& Burnham, 2011] para, em seguida, propor uma nova visão deste fenômeno, até chegar na definição da convergência tecnologia líquida, posta na seção anterior; (2) desenvolvemos uma pesquisa piloto [Santos, Duran \& Burnham, 2013], na qual, através de observação participante, investigamos a rotina de estudantes que usavam ciberinstrumentos móveis durante as aulas de uma disciplina de pós-graduação.

A partir dos achados desta pesquisa inicial, partimos para uma mais ampla. Nesta última, contamos com a participação de 99 estudantes, distribuídos em três turmas (duas de graduação e uma de pós-graduação) de três cursos distintos, cada um de uma 
universidade pública diferente. Eram 48 homens e 51 mulheres, com média de idade de 23,3 e desvio padrão de 8,6.

O levantamento de informações aconteceu através de: (1) observação participante, repetindo a mesma estratégia da pesquisa piloto, contando inclusive anotações de campo. O período de observação durou um semestre letivo; (2) entrevistas individuais, selecionando 15 estudantes, tanto os que eram usuários frequentes de ciberinstrumentos durante a aula quanto os que não eram; (3) questionário, com taxa de resposta efetiva de $46,5 \%$, ou seja, foram validadas as respostas de 46 estudantes; e (4) pesquisa bibliográfica, buscando referenciais multidisciplinares para auxiliar e aprofundar os achados da investigação.

Já a etapa de análise consistiu de: (1) análise de conteúdo para fazer a codificação das entrevistas; (2) estatística descritiva, para sumarizar os resultados do questionário; e (3) análise contrastiva para não apenas organizar as idéias de autores da revisão bibliográfica como também para facilitar uma triangulação com os resultados da análise de conteúdo das entrevistas e do sumário quantitativo do questionários.

\section{Convergência tecnológica}

Após a realização de uma variada revisão bibliográfica, os principais significados atribuídos à expressão convergência tecnológica foram os seguintes [Santos, 2011]: (1) infra-estrutura comum para diversos serviços, como acontece com o backbone da Internet; (2) conteúdo multimídia, no que diz respeito a integração de diversas mídias como texto, áudio, vídeo e imagens; (3) convergência de indústrias e mercados, se referindo a fusões entre indústrias de informação e comunidação; (4) multidisciplinaridade, envolvendo novas áreas de conhecimento como a própria tecnologia de informação; (5) multifuncionalidade, sobretudo, presente em ciberinstrumentos, nos quais a variedade de funcionalidades tem crescido acentuadamente; (6) convergência de serviços, quando um mesmo serviço é oferecido a diversas plataformas, proporcionando a interoperabilidade.

Tais significados não estão isolados, pelo contrário, têm uma relação muito próxima. A partir das infra-estruturas digitais e/ou de rede em comum geram-se produtos, geralmente, envolvendo confusamente conteúdos multimídia, multifuncionalidades e convergência de serviços. O sustentáculo desse aparato tecnológico, do ponto de vista do conhecimento, é a multidisciplinaridade, e da perspectiva financeira, é o resultado da convergência da indústria e seus mercados.

Neste ínterim, juntamos o fato de os mais diversos objetos eletroeletrônicos com funcionalidades info-comunicacionais se multiplicarem ao longo das décadas, contendo e sendo contidos uns pelos outros, coexistindo não necessariamente de forma harmoniosa, mas complexa [Morin, 2007]. Isso aponta para um caráter plural e não unânime da convergência tecnológica. Daí que definimos convergência tecnológica como fenômeno de proliferação e coexistência confusa dos mais diversos objetos perceptíveis e imperceptíveis - do cotidiano com funcionalidades infocomunicacionais, que se intercomunicam de forma heterogênea, seja por iniciativa humana ou não - vide programações automáticas e/ou baseada em inteligência artificial —, promovendo intercâmbio crescente de informações. 
A convergência tecnológica líquida, cuja definição está na seção introdutória deste trabalho, é um recorte significativo deste universo, dando uma ênfase nos ciberinstrumentos móveis. Nesta visão, identificamos as seguintes tendências: (1) aumento do número de ciberinstrumentos móveis em detrimento da diminuição dos não móveis; (2) coexistência de ciberinstrumentos móveis com funcionalidades semelhantes como acontece com pessoas que possuem tanto um netbook quanto uma tablet.

Além disso, defendemos que a própria estrutura da convergência tecnológica líquida, formada pela sua infraestrutura física, informações e sociedade, é marcada pela fluidez. Para entendermos melhor, Bauman (2001) advoga que a característica mais marcante da sociedade atual é a fluidez, que quer dizer que tudo ou quase tudo é incapaz de manter a sua forma por muito tempo. Crenças, instituições, estilos de vida, tecnologias mudam antes mesmo de se tornarem costumes, tradições, verdades, ou seja, antes de se "solidificarem". Tudo agora é líquido, "não se atém muito a qualquer forma e está constantemente pronto (e propenso) a mudar" [Bauman, 2001, p. 8].

Assim, vemos que a infraestrutura da convergência líquida, formada por inúmeras tecnologias, são renovadas rotineiramente ao passo que em poucos anos correse o risco de ficar obsoleta.

A informação também não fica atrás. Podem ser mixadas de diversas formas: "texto, imagem e som já não são o que costumavam ser. Deslizam uns para os outros, sobrepõem-se, complementam-se, confraternizam-se, unem-se, separam-se e entrecruzam-se. Tornaram-se leves, perambulantes. Perderam a estabilidade que a força de gravidade dos suportes fixos lhes emprestavam" [Santaella, p. 24, 2007]. Além disso, a própria renovação do saber tem sido uma tônica constante. O conhecimento adquirido ontem já foi ultrapassado por um novo, produzido hoje [Bauman, 2009].

Finalmente, como colocamos, a própria sociedade em si tem sido marcada pela fluidez, ou melhor, os relacionamentos humanos têm-se revelado frágeis, com sentimentos de insegurança que geram desejos conflitantes de estreitar os laços ao mesmo tempo em que se deseja afrouxá-los. Usando uma metáfora apropriada ao meio cibernético, podemos dizer que os relacionamentos se assemelham às redes, com uma facilidade tanto de conexão quanto de desconexão [Bauman, 2004].

\section{Resultados e discussão}

Primeiramente, podemos afirmar que o fenômeno da convergência tecnológica líquida estava patente nas salas de aulas investigadas. Em todas as turmas, os sujeitos possuem mais ciberinstrumentos móveis do que não móveis (computadores desktops). Além disso, nota-se uma tendência dos ciberinstrumentos móveis coexistirem confusamente, ou seja, alguns estudantes possuem mais de um, usando conforme julgar mais adequado, como o caso dos que possuem, por exemplo, notebooks e netbooks.

No que diz respeito ao uso em sala de aula, a presença de ciberinstrumentos móveis variou, em média, entre $8,7 \%$ e $23,1 \%$ do total de estudantes presentes - aqui não foram contados celulares, mas apenas notebooks, netbooks e tablets. É importante afirmar que essa taxa de uso foi suficiente para desenvolver uma pesquisa substancial sobre o tema.

Quanto à natureza das atividades praticadas com estes ciberinstrumentos pode-se 
dizer que foram usados com propósitos mais acadêmicos pelos pós-graduandos. Já os graduando os usaram mais para atividades não relacionadas às aulas, entre elas, uso de e-mail e de redes sociais. Quando associado à aula, como nos casos dos pósgraduandos, as principais atividades desenvolvidas foram registro de apontamentos, acesso ao material didático e pesquisa através de buscadores.

Claramente, o desafio-mor deste uso é a dispersão, a atenção em sala de aula. Por isso, demos um destaque especial a este tema analisando-o sob um olhar multidisciplinar.

\subsection{Convergência em sala de aula sob a ótica da Psicologia Cognitiva}

A atenção humana tem estreita relação com o uso de ciberinstrumentos, ou melhor, com o comportamento multitarefas envolvido neste uso. Nestes casos, ela pode ser alternada, quando a atenção do indivíduo oscila entre um e outro(s) foco(s), ou dividida, quando se concentra em mais de um foco. Ambas envolvem mais de um estímulo, se diferenciando pela forma como respondem: de maneira alternada ou simultânea [Lima, 2005].

No caso da atenção dividida, a qualidade das tarefas executadas simultaneamente pode variar em função de três aspectos, pelo menos: (1) a prática, que com o tempo pode fazer com que o sujeito desempenhe melhor a atividade em foco; (2) o grau de complexidade, que pode demandar mais ou menos atenção; (3) grau de similaridade entre as tarefas quanto à percepção sensorial, por exemplo, se são usados canais diferentes, visual e auditivo, as chances de melhorar o desempenho pode ser maior [Eysenck \& Keane, 2007].

Trazendo para a sala de aula, embora jovens disponham de uma capacidade reconhecida de comportamento multitarefas [Tapscott, 2010], não foi bem o que encontramos. Nosso trabalho corrobora com resultados de outras pesquisas que apontam para uma tendência de que os ciberinstrumentos móveis, quando não orientados pedagogicamente, ocasionem dispersões em sala de aula. Mais especificamente, a maioria delas indica uma correlação negativa entre o uso de ciberinstrumentos e o desempenho acadêmico [Hembrooke \& Gay, 2003; Fried, 2008; Kirschner \& Karpinski, 2010; Kay \& Lauricella, 2011; Junco \& Cotten, 2012].

Em nosso campo de investigação, quando perguntamos aos entrevistados se suas atenções se portam diferente quando do uso de ciberinstrumentos móveis, 93,3\% concordou que sim, sendo que $80 \%$ demonstrou ter uma repercussão negativa em suas atividades acadêmicas. As tecnologias mais interativas são aquelas que demonstram atrair um maior uso e ao mesmo tempo uma maior dispersão em relação a aula, como é o caso do Facebook, com uma grande número de funcionalidades e alto grau de popularidade entre o corpo discente - e até mesmo, de uma forma mais geral, entre a população. Vale ressaltar que o uso destas tecnologias não raro já está incorporado de forma automática a sua rotina como acontece com o chamado hábito de verificação, isto é, a inspeção breve e repetitiva de conteúdo dinâmico rapidamente acessível através de ciberinstrumentos móveis [Oulasvirta et al, 2012]. Em nossa pesquisa, 63\% dos que responderem ao questionário concordaram, em algum grau — totalmente ou parcialmente -, ter tal hábito.

Notamos ainda que o uso intenso dessas tecnologias acaba por provocar uma espécie de efeito colateral em seus usuários, que repercutem também nos estudos, como 
colocou uma das respondentes ao questionário: "sinto-me a cada dia mais refém de atividades antes corriqueiras como checar o e-mail e verificar minhas redes sociais. Concluo que tenho estudado menos ou de maneira mais superficial porque fico conectada mesmo quando estou lendo um texto acadêmico". De forma mais geral, em nosso questionário, $50 \%$ dos graduandos concordaram, em algum grau, usar a Internet em quantidade cada vez maior de tempo para atingir satisfação. Já outros 33\% confirmam de alguma maneira que se esforçam repetidamente, mas sem sucesso, controlar, cortar ou para o uso de Internet. É uma realidade que demonstra precisar de um maior cuidado.

É importante destacar ainda que em relação aos pós-graduandos, os graduandos revelaram ter uma maior dificuldade de concentração e terem suas atividades mais prejudicadas quando da divisão da atenção. Não que estes sejam tenham menor capacidade de comportamento multitarefas, mas eles a praticam mais, como notamos nos instrumentos de levantamento de informações, o que confirma uma certa relação entre comportamento multitarefas e dispersão em sala de aula. Neste caso, além das evidências já pontuadas, uma outra é que 50\% dos graduandos entrevistados disseram não levar ciberinstrumentos para a sala de aula para evitar se dispersarem ao usá-los.

\subsection{Convergência em sala de aula sob a ótica da Educação}

A despeito de tantas iniciativas coletivas proporcionadas pelo uso de ciberinstrumentos móveis, sobretudo através das redes sociais, percebemos na nossa pesquisa que, em sala de aula, tais ciberinstrumentos estão muito mais a serviço de atividades individuais do que coletivas. Isso fica evidente se relembrarmos as atividades mais praticadas, apontadas anteriormente: registro de apontamentos, acesso a material didático e uso de buscadores.

Quando intimados a emitirem um parecer a respeito do uso de ciberinstrumentos móveis em sala de aula, 46,7\% dos entrevistados demonstraram ser positivo, mas com ressalvas. Em outras palavras, queriam se referir ao fato de que depende de quem usa e/ou como usa. De qualquer forma, não deixa de ser um indicativo do risco de dispersão, do cuidado inerente que se precisa ter na utilização.

Neste cenário, o que o corpo discente espera dos professores é que estes se apropriem dos ciberinstrumentos de forma mais contextualizada com a aula em vez de ignorá-los, além de procurar ser criativos o suficiente para evitar a dispersão em sala. Por outro lado, os estudantes assumem a responsabilidade de estarem conscientes de que é papel deles estarem atentos às aulas em vez de assuntos não relacionados com elas.

Deste uso intenso de tecnologia, percebemos que a dispersão, no âmbito pessoal, tem potencializado um processo que denominamos de construção fragmentada do conhecimento, isto é, processo de geração de conhecimento atravessado por fluxos de informações não relacionadas devido a interrupções frequentes e repetitivas ocasionadas por diversos motivos. O próprio hábito de verificação, por exemplo, proporciona tal comportamento. Podemos dizer que se trata de uma atenção fluida, que alterna ou divide frequentemente o seu foco atencional do conteúdo da aula, num ir e vir constante.

Vale ressaltar que a forma de usar os ciberinstrumentos também depende de algumas variáveis como disposição do espaço físico e método de construção de conhecimento utilizado. O primeiro caso ficou bastante claro quando, em nossa pesquisa 
piloto, tivemos dois momentos ao longo do semestre, cada qual com uma disposição física distinta. Aquela formada em círculo, onde todos viam todos frente a frente, se sobressaiu positivamente em relação à outra, na qual a distribuição entre estudantes era mais espaçosa e não era possível ver todos ao mesmo tempo.

Já quanto ao método de construção de conhecimento, ficou bastante evidente que o método Problem-Based Learning (PBL) —, usado em uma das turmas investigadas, proporcionou um uso mais contextualizado com a discussão dos estudantes. Tal método tem uma abordagem centrada no estudante, na qual a partir de um problema proposto, que se aproxima com a realidade do mercado de trabalho, os estudantes discutem em grupo uma solução ao longo de algumas sessões (aulas). Aqui o professor sai de cena, ou melhor, de um papel protagonista, para assumir uma papel secundário, como tutor, acompanhando e, apenas quando necessário, orientando o grupo [Deslile, 1997]. Embora os ciberinstrumentos continuassem sendo usado pelos discentes sem orientação pedagógica, nestes casos os estudantes tendiam a usá-los como forma de contribuir na discussão do grupo, ou seja, direcionado a uma esfera mais coletiva do que individual. Isso tanto foi notado na observação participante quanto foi relatado nas entrevistas.

\subsection{Convergência em sala de aula sob a ótica da Sociologia}

Além da perspectivas da Psicologia e da Educação, também analisamos nosso objeto de estudo e, em especial, a questão da atenção em sala de aula sob a perspectiva da Sociologia, principalmente, a partir do pensamento de Zygmunt Bauman.

De início, é essencial dizer que não apenas a tecnologia é fruto da cultura atual, mas também que esta é potencializada por aquela. De modo recursivo, a sociedade produz tecnologias que, por sua vez, acabam por interferir na própria sociedade, e assim por diante [Morin, 2007]. Para ilustrar, podemos nos referir ao ritmo de vida que tem acelerado nas últimas décadas. A tecnologia não deixa de ser influenciada por isso. Por um lado, novos modelos de ciberinstrumentos móveis são lançados sucessivamente em um curto período de tempo. Por outro lado, o próprio uso deles provoca uma aceleração da vida humana na medida que, além de exigir atualizações frequentes de interfaces, aplicativos e funcionalidades, permite e estimula lidar com um fluxo informacional crescente a todo momento, inclusive, em sala de aula. Os estudantes deixaram muito claro isso, a exemplo de dois relatos: (1) "é a necessidade de (...) terminar logo tudo, né, de fazer todas as coisas que estão pendentes."; e (2) "Ou você tá fazendo o texto e tá conversando com alguém e na mesma da hora volta a fazer o texto. Então, é uma loucura assim, um 'vu, vu, vu, vu, vu...'. (...) Então, é uma agonia de vida”. Em suma, ao mesmo tempo em que os ciberinstrumentos de uma cultura da aceleração, do imediato, também contribuem com ela, ou melhor, a potencializam. Esta característica se reporta justamente ao caráter fluido — líquido — de nossa sociedade.

Em especial, as práticas educativas, além de apontar para uma necessidade de serem renovadas incessantemente, a fim de contextualizar a tecnologia, também parece que se exige, sobretudo da parte discente, que o entretenimento faça parte de tais práticas. Essa alternativa é extremamente valiosa desde que não se torne um fim em si mesma. Quando acontece uma falta momentânea de estímulos interessantes na aula seja por já conhecerem o assunto, por a aula ou o seu conteúdo serem enfadonhos ou qualquer outro motivo, os estudantes se sentem entediados. Esse foi um ponto muito 
colocado por eles, a exemplo do depoimento de um dos entrevistados: "quando a aula tá chata mesmo - e eu não quero sair, quero fica na aula - eu pego o notebook de alguém (...) pra acessar à Internet". Nestes casos, em vez do ciberinstrumento móvel ser posto a favor da construção coletiva do conhecimento, é colocado para alcançar outros objetivos, objetivos estes que não necessariamente se trata de construções de conhecimento, mas mero consumo do tempo.

Neste jogo, professores parecem precisar adotar os princípios de "[1] impacto máximo, uma vez que a nossa imaginação submetida a choques constantes se tornou blasée e são necessários para a estimular choques cada vez mais fortes, cada um deles mais arrasador do que o precedente, e [2] obsolescência imediata, uma vez que a nossa atenção tem uma capacidade limitada e é preciso libertar um espaço que possa absorver novas celebridades, modas, obsessões ou "problemas"” [Bauman, 1995, p. 269, grifo nosso]. Não é qualquer coisa que vai atrair a atenção, ainda mais com demandas extremamente atrativas reclamando nos ciberinstrumentos de cada discente.

Retomando a questão posta na seção anterior, que ciberinstrumentos foram usados mais para fins individuais do que coletivos, temos um desafio presente aqui, patente em nossa sociedade: o individualismo. Embora se pense que estar em silêncio em um ciberinstrumento não atrapalha a aula, como expôs um aluno na entrevista, isso pode ser um equívoco, um jeito de pensar limitado; pois, a medida que um sujeito se omite de participar do processo de construção de conhecimento -, ele deixa de enriquecê-lo, de contribuir para uma visão mais diversificada e ampla. O perigo do individualismo é justamente o sujeito olhar apenas para aquilo que interessa a si próprio, não se abrindo a um encontro mais profundo com o Outro. Nestes casos, relacionamentos acabam sendo pautados pelo Eu-Isso, em que, para Buber (2001), tudo se torna passível de uso, de experimentação ou, ainda mais, de domínio. O infinito de Outrem é, então, substituído pelo desejo infinito de outros infinitos desejos calculadamente incutidos nos ciberinstrumentos móveis.

\section{Considerações Finais}

A convergência tecnológica líquida em sala de aula se apresenta com um elemento altamente desafiador da perspectiva pedagógica. Nosso objetivo foi analisar tal fenômeno, seu status quo a partir da percepção discente, em especial, na realidade do ensino superior público da Bahia. Neste artigo apresentados os principais achados e conclusões de nossa pesquisa.

Embora a sala de aula, enquanto espaço de convivência humano, esteja marcada pelo caráter fluido da sociedade atual, a estrutura pedagógica parece diferir dela, não estando preparada para tratá-la. O mundo fora da instituição educacional cresceu diferente daquele preparado dentro dela, aonde, dentre outros aspectos, estava preparada para oferecer um pacote de conhecimentos que serviria por toda vida ao futuro profissional. Nesta perspectiva, de uma maneira ou de outra, essa pesquisa expõe feridas ainda muito abertas dos métodos de construção do conhecimento em voga em nossas universidades, salvo raras exceções, as quais estão longe de serem cicatrizadas. Este cenário pressiona ainda mais a (re)pensarmos os pressupostos vigentes na educação, em especial, a universitária. A abertura para o Outro é apenas o primeiro passo rumo à busca de alternativas adequadas. É a essência do processo educativo. 
Outras contribuições desta tese são: (1) uma revisão sistemática da expressão convergência tecnológica, além de discuti-la e propor uma nova visão em torno dela; (2) a análise multidisciplinar, na qual os referenciais utilizados, estabelecendo um constante diálogo com a exploração empírica, permitiu-nos interpretar mais ricamente a problemática em foco se comparada às abordagens que até então vinham sendo adotadas, como indicado na Introdução, as quais, de maneira geral, eram essencialmente positivistas; (3) abordagem qualitativa, através da qual conseguimos adentrar o cotidiano discente durante as aulas de maneira mais profunda, acessando as motivações para usar ou não ciberinstrumentos, observando frequências de uso in loco, entrando em contato com o movimento dos olhares, notando fragmentos de construção de conhecimento, entre tantos outros aspectos.

Como perspectivas de pesquisa, a principal se remete a ampliação do campo empírico, em vários sentidos, tais como: (1) aumentar o número de classes incluídas na pesquisa, podendo, assim, revelar variações peculiares de cada área de conhecimento e até culturais, relativas às idiossincrasias de região ou da(s) própria(s) universidade(s) em foco na investigação; (2) abranger atividades acadêmicas extra-classe, que amplia o espaço (in)formacional da sala de aula para além da dimensão apenas temporal daquele período de aula; (3) incluir a visão de professores, pois, embora tenhamos discutido a postura deles, não foi a partir de seus próprios olhares, mas sim dos estudantes. Então, poderia se averiguar, por exemplo, a opinião deles sobre o uso de ciberinstrumentos móveis em sala de aula (e fora dela) e como têm lidado com a dispersão.

\section{Referências Bibliográficas}

Barbosa, A. F. (2010). Pesquisa sobre o Uso das Tecnologias da Informação e da Comunicação no Brasil: TIC Domicílios e TIC Empresas 2009. São Paulo. Disponível em: <http://www.cetic.br/tic/2009/index.htm>. Acesso em: 02 junho 2011.

Barbosa, A. F. (2011). Pesquisa sobre o Uso das Tecnologias da Informação e da Comunicação no Brasil: TIC Domicílios e TIC Empresas 2010. São Paulo. Disponível em: <http://www.cetic.br/tic/2010/index.htm>. Acesso em: 02 fevereiro 2012.

Bauman, Z. (1995). A vida fragmentada: ensaios sobre a moral pós-moderna. Relógio D'Água, Lisboa.

Bauman, Z. (2001). Modernidade líquida. Jorge Zahar Ed., Rio de Janeiro.

Bauman, Z. (2004). Amor líquido. Jorge Zahar Ed., Rio de Janeiro.

Bauman, Z. (2009). Zigmunt bauman: Entrevista sobre a educação, desafios pedagógicos e modernidade líquida. Cadernos de pesquisa, v. 39, n. 137, p. 661-684.

Buber, M. (2001). Eu e Tu. Liber Livro Editora, Ed. Centauro.

Dahlstrom, E. et al. The ECAR National Study of Undergraduate Students and Information Technolo-gy, 2011. Relatório técnico. 2011.

Delisle, Robert. (1997). How to use problem-based learning in the classroom, ASCD.

Eysenck, M. W. \& Keane, M. T. (2007). Manual de Psicologia Cognitiva. Artmet, Porto 
Alegre.

Fried, C. B. (2008). In-class laptop use and its effects on student learning. Computers \& Education, v. 50, n. 3, p. 906-914.

Hembrooke, H. \& Gay, G. (2003). The laptop and the lecture: The effects of multitasking in learning environments. Journal of Computing in Higher Education, v. 15 , n. 1, p. 46-64.

Junco, R. \& Cotten, S. R. (2012). No a 4u: The relationship between multitasking and academic performance. Computers \& Education, n. 59, v. 2, p. 505-514.

Kay, R. \& Lauricella, S. (2011). Unstructured vs. structured use of laptops in higher education. Journal of Information Technology Education: Innovations in Practice, v.10, p. 33-42.

Kirschner, P. A. \& Karpinski, A. C. (2010). Facebook and academic performance. Computers \& Education, v. 26, n. 6, p. 1237-1245.

L. Vigotski. A formação social da mente: o desen-volvimento dos processos psicológicos superiores. São Paulo, Martis Fontes, 2007.

Morin, E. (2007). Introdução ao pensamento complexo. Editora Sulina, Porto Alegre.

Oulasvirta, A.; Rattenbury, T.; MA, L.; Raita, E. (2012). Habits make smartphone use more pervasive. CyberPsychology \& Behavior, v. 16, n. 1, p. 105-114.

R. Lima. (2005). Compreendendo os mecanismos atencionais. Ciência e Cognição, v. 6, p. 113-122.

Santaella, L. (2007). Linguagens líquidas na era da mobilidade. Paulus, São Paulo.

Santos, D. M. B., Duran, A. A. \& Burnham, T. F. (2011). After the all, what is technological convergence!? In: IADIS e-Society 2011. Avila, Espanha.

Santos, D. M. B., Duran, A. A. \& Burnham, T. F. (2012). Dispositivos móveis em sala de aula: Uma revisão bibliográfica. In: Anais do II Congresso Internacional TIC e Educação. Lisboa, Portugal: p. 3222-3233.

Santos, D. M. B., Duran, A. A. \& Burnham, T. F. (2013). Processos de construção do conheci-mento em sala de aula mediados pela convergência tecnológica: reflexões deste cenário emergente. Revista Brasileira de Informática na Educação, v. 20, n. 3.

Smith, A. (2010). Mobile Access 2010. Washington. Disponível em: <http://www.pewinternet.org/Reports/2010/Mobile-Access-2010>. Acesso em: 01 junho 2011.

Tapscott, D. (2010). A hora da geração digital: como os jovens que cresceram usando a Internet estão mudando tudo, das empresas aos governos. Agir Negócios, Rio de Janeiro.

Vigotski, L. (2007). A formação social da mente: o desenvolvimento dos processos psicológicos superiores. Martis Fontes, São Paulo.

Wood, E., Zivcakova, L., Gentile, P., Archer, K., Pasquale, D. D., Nosko, A. (2012). Examining the impact of off-task multi-tasking with technology on real-time classroom learning. Computers \& Education, v. 58, n. 1, p. 365-374. 